\title{
ISSUING PRESCRIPTIONS BY THE PHARMACISTS TO ENSURE CONTINUITY OF MEDICAL TREATMENT. LEGAL PRINCIPLES CONCERNING A NEW TYPOLOGY OF PRESCRIPTIONS
}

\author{
RAFAŁ PATRYN and MARIOLA DROZD*
}

Chair and Department of Humanities and Social Medicine, Medical University of Lublin, Poland

\begin{abstract}
At present, the pharmacist is allowed to issue 3 types of prescriptions for medicinal products. The Act on the profession of pharmacist of 10 December 2020 defines a new and very important extended occupational power of the pharmacist, i.e. the pharmacist's right to issue prescriptions to maintain continuity of medical treatment originally ordered by a primary care provider. The term used for this type of prescription is a repeat prescription. Since this largely enhanced occupational power of pharmacists involves several areas of legal regulations and detailed solutions, it deserves presentation. It is worth noting that the amendment of the law connected with COVID-19 prevention specifies alternations in the scope of heretofore pharmacists 'occupational powers. Now they are authorized to write prescriptions for themselves (pro auctore), their family (pro familiae) as well as pharmaceutical prescriptions in the case of health and situations of dangering of life. Moreover, the new Act enhances this occupational power even further and approves it as a part of the pharmaceutical patient care provided by the pharmacist. The term "a repeat prescription" refers to a prescription issued by a pharmacist to ensure continuity of medical treatment and it should be understood as a prescription renewed by a pharmacist to facilitate the continuation of treatment originally prescribed by the physician. This paper presents legislative regulations and details regarding this form of exercising occupational powers by the pharmacist together with outlining the conditions and essential elements of the procedure of issuing interpreted prescriptions.
\end{abstract}

Keywords: law, prescriptions, continuity, occupational powers, pharmacist

The law amendment introduced in 2020, mainly because of the COVID-19 pandemic, also applied to the profession of pharmacist. In order to address health service demands and ensure better use of the potential of health workforce during the COVID-19 pandemic, including pharmacists (1), the Act on Pharmaceutical Law has been amended and the Act on the profession of pharmacist has been passed, moreover, alternations have been made in other legal acts. The recently introduced amendments lay out new regulations concerning the pharmacist's professional conduct in the case of having to deal with specific situations (emergency care); the pharmacist is also granted authorization to continue the medical treatment originally prescribed by the doctor. Generally, after implementation of the abovementioned alternations, pharmacists have become authorized to issue three types of prescriptions (i.e. pro auctore, pro familiae; a pharmaceutical prescription, and a repeat prescription which ensures the continuity of the doctor's orders). Now, due to being granted authorization to issue specific prescriptions, the pharmacist has the right to renew prescriptions issued by the primary care provider. This has become the pharmacists` extended duty formally added to their heretofore scope of duties ensuring the provision of pharmaceutical care to the patient. This concept is also new with respect to the occupational powers of this group of health care workers. The scope of this type of care is laid out in the newly established Act on the profession of pharmacist.

In the period of January 2020 - July 2020, over 207 million e-prescriptions were issued, which constituted $90 \%$ of all the issued prescriptions. At that time, about 20.5 million patients were prescribed eprescriptions and the majority of them were within the age range of 61-70 years. From January 2020 to June 2020, 18 thousand medical doctors issued over 4 million e-prescriptions for medicines to be used within a 360-day treatment. More than 1 million patients took this opportunity. On average, from January to June 2020 doctors issued about 1.2 million

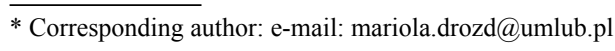


e-prescriptions daily, although there were also record numbers, e.g. in March, 2 million e-prescriptions were issued in one day. Most of the issued eprescriptions were for hypotensives, medicines for heart failure, coronary disease, cardiac ischemia, medicines reducing cholesterol levels as well as drugs for diabetic patients (2). It should be noted that because of the large number of pharmacies in Poland (in January 2021, the number of community pharmacies was 12 202), they are easily accessible health care facilities, also open on public holidays or at night, and counseling is provided there without waiting (3). In reality (since the very introduction of Act on the profession of pharmacist - on the day the manuscript was prepared, the Act had not been published in the Journal of Laws yet) an authorized pharmacist has the right to issue a repeat prescription as a part of providing the pharmaceutical care.

It is an essential novelty in the legal regulations specifying the occupational powers of pharmacists. Thus, the concept of a repeat prescription literally pertains to a prescription issued by a pharmacist as a continuation of the treatment originally started by the doctor. A great advantage of this approach is that it ensures the patient's easy access to medication (and treatment) and at the same time allows the pharmacist to make use of their medical knowledge for proper assessment of the efficacy of the pharmacotherapy applied. It is an occupational power that agrees with the assumptions which, in order to address the health service demand, aim at expanding health workforce and use the potential of pharmacists in the Polish system of health care, which is directly expressed in the document "State Drug Policy 2018-2022"(4). This solution is important in the management of chronically ill patients. In dependent prescribing, the pharmacist renews a prescription originally issued by the primary care provider. Authorized pharmacists should substitute for doctors in a prescribing role after pharmaceutical consultations have been conducted, necessary diagnostic tests performed and it is certain that the drugs are safe and effective for the patient. A repeat prescription as an element of pharmaceutical care is to be a reimbursed prescription, and the drug reimbursement level is similar to this in the case of the original prescription (i.e. the prescription originally issued by the doctor).

It is worth mentioning that in other countries, in order to ensure continuity of the launched treatment, pharmacists are allowed to write prescriptions for patients with chronic diseases $(5,6)$. Analysis of pharmacists' occupational powers enabling them to issue prescriptions in other countries shows that in many of them the pharmacist has a much greater scope of competence than mere permission to keep up doctor's orders. For instance, in Great Britain, the United States, New Zealand, and Australia the pharmacist independently prescribes medication for the patient (7). In the Polish health care system, a repeat prescription service has been in operation since January $1^{\text {st }}, 2016$, and applies to nurses and midwives, which is specified in the Act on the nursing and midwifery professions (8).

\section{Basic legislation for pharmacists' new occupational powers. Types of prescriptions pharmacists are authorized to issue}

Basic legislation, i.e. specification of applicable principles and rules of professional conduct for pharmacists, has been changed to increase the range of powers in pharmaceutical care. Before the changes were introduced, the pharmacist was allowed to issue so-called pharmaceutical prescriptions in the case situations of dangering of life. Later, the Act of March 31, 2020, on amending certain acts in the field of health care system related to preventing, counteracting and combating COVID-19 added an entry to the Act on Pharmaceutical Law on enhancing the possibilities of issuing a pharmaceutical prescription which authorized the pharmacist's occupational power to issue a prescription for an individual in a health-jeopardizing situation as well as new powers to issue reimbursed pro auctore and pro familiae prescriptions. The Act on the profession of pharmacist passed recently has granted pharmacists a new right and now they are allowed to issue prescriptions to ensure continuity of medical treatment. The Regulation of the Minister of Health of December 23, 2020, on prescriptions, defines a health worker authorized to issue prescriptions as the person discussed in Art. 2 point 14 of the Act of May 12, 2011, on the reimbursement of medicines, foodstuffs intended for particular nutritional uses and medical devices. This also applies to the profession of pharmacist, which is defined in Art. 96 point 4 of the Act of September 6, 2001, the Act on Pharmaceutical law (9). Additionally, the regulation on reimbursement specifies that a licensed medical professional who conforms with the requirements of their profession is authorized to issue prescriptions, which is in compliance with the Act on the reimbursement of medicines, foodstuffs intended for particular nutritional uses and medical devices, it also remains in compliance with the $A c t$ on Pharmaceutical Law. According to this added regulation, pharmacists are allowed to place orders to ensure continued supplies of medicinal products 
specified in Art. 38 (10). It should be explained that a person practicing a medical profession is someone who, on the basis of separate regulations, is authorized to provide health services and a person fully qualified to be granted authority to provide health services in a specified scope of powers or in a specified medical field (11). Undoubtedly the profession of pharmacist meets all the requirements; therefore, in the light of legal regulations, it is pharmacists, among other health workers, who are granted permission to issue prescriptions.

The Act on Pharmaceutical Law amended by the Coronavirus Act, set in motion new principles regarding issuing prescriptions by pharmacists, and this amendment concerns situations of dangering of life (art. 96, act 4) a pharmacist who has a license to practice pharmaceutical profession is allowed to issue a prescription for a person defined in art. $95 \mathrm{~b}$ act 3, or a pharmaceutical prescription-in the case of a health-jeopardizing situation for the patient (...), this section is added to the already existing statutory provision concerning the pharmacist's professional conduct in a specific situation, i.e. a dangering of life (art. 96, act 3) (12). In the case of a sudden threat to a patient's life, a licensed pharmacist is allowed to dispense a medicinal product subject to a medical prescription in the smallest therapeutic packaging without a doctor's prescription, with exclusion of intoxicating substances, psychotropic substances and Category 1 precursors. The Act on Pharmaceutical Law specifies what types of prescriptions may be issued by the licensed Polish pharmacist. The first type of prescription is for the pharmacist's use (pro auctore), the second type is for their family (pro familiae). Prescriptions pro auctore and pro familiae may be issued for:

- the spouse;

- the common-law partner;

- a relative of the first degree of kinship (in the straight line);

- a relative of the second degree of kinship, i.e. siblings of the person issuing the prescription and the siblings' children (in the lateral line). Such prescriptions may be issued as paper or electronic prescriptions (12).

While issuing a pro auctore prescription or a pro familiae prescription, the pharmacist is obliged to keep a list of prescriptions that contains:

1) the consecutive number of an entry

2) the date of issue of the prescription

3) the patient's ID number (PESEL) - in the case of a newborn - the mother's PESEL number, when there is no PESEL, the identity document number
4) the diagnosis of the disease, health issue, or injury

5) the international or Polish name of the medicinal product, food product for particular nutritional uses, or the generic/ commercial name of the medical product

6) the dosage forms of the medicinal product, food product for particular nutritional use or a medical product which is to be dispensed, if on the market there is more than one dosage form

7) the dose of a medicinal product or a food product intended for particular nutritional use if it is available on the market in more than one dose

8) the amount of a medicinal product, food product for particular nutritional use or a medical product, and in the case of a medicinal product in the form of a magistral preparation - the name and amount of the pharmaceutical raw materials (ingredients) which are to be used to make it

9) the dosage method.

When authorized pharmacists have to deal with a health-jeopardizing situation, they are allowed to issue another type of prescription. It is mandatory, however, that such a prescription should include information clarifying the reason why a certain medicine was issued (e.g. health-saving because of COVID-19). In the case of this type of prescription, the pharmacist is allowed to prescribe more than one smallest packaging of a given product. The legal acts introduced in 2020 to counteract the COVID-19 pandemic also extended the occupational powers of the pharmacist. A licensed pharmacist is allowed to issue a pharmaceutical prescription when a patient's health is jeopardized, e.g. because of COVID-19 (13). This type of prescription is an e-prescription; however, in certain situations issuing a paper prescription is also allowed. It is exercised in the case of:

1) no access to the proper ICT system

2) issuing a prescription for an unidentified person

3) issuing a prescription by a pharmacist defined in art. 6 of Act 1 of April 19, 1991, on pharmacy councils in the light of which the pharmacist is an EU citizen, relocates to the Republic of Poland for the first time in order to temporarily and occasionally fulfill the professional duties of the pharmacist

4) eligibility to prescribe medicinal products of the Rx availability category, with the exclusion of those medicinal products which 
contain intoxicating substances and psychotropic substances

5) inclusion of the necessary information and the cause of issuing the prescription

6) the prescription is issued with a $100 \%$ payment, except for "pro auctore" and "pro familiae" prescriptions

7) the necessity of keeping a record of the paper prescription after it has been issued

8) application of regulations specified by the Act 4-5 art. 96a accordingly, i.e. information about the prescribed medicinal product, food product intended for particular nutritional use, or a medical product (point 4) as well as information about the date of issue are included (point 5) (13).

The Regulation of the Minister of Health of April 17, 2020, amending the regulation on prescriptions, i.e. Regulation of the Minister of Health of April 13, 2018, on prescriptions, was important because it introduced labeling of prescriptions issued by pharmacists (14). Two digits: 04 are the identification number of such a prescription (in the block of 10), also in the identification number of an authorized person (Annex 5 to Part I of Regulation) there is a specified identification of a medical worker, which in the case of a pharmacist has the value of " 8 ", and then the digits from 2 to 9 assume an 8-digit number which is the number certifying a pharmacist's entitlement to practice pharmacy and the same number is found on the list of the Central Register of Pharmacists.

According to art.4 of Act on the profession of pharmacist, practicing pharmacy aims at patient health protection as well as protection of the public health and, according to Point 1 , it involves the provision of a wide scope of pharmaceutical services (15). This type of care is defined in Act 2. According to this specification and within the meaning of the law, pharmacists provide and document pharmaceutical care which is a process involving collaboration both with the patient and the attending physician as well as with other medical professionals, whenever necessary; they supervise the correct course of individual pharmacotherapy, which, according to Point 5, includes collaborative prescribing services (16). It is the third type of prescription the pharmacist is authorized to prescribe (Figure 1).

\section{DISCUSSION}

Issuing prescriptions by the pharmacist to ensure continuity of the doctor's order is a new occupational power in the scope of the pharmacist's duties which is still being implemented. However, at this stage, one essential thing regarding this occupational power should be noted. This power is a part of the pharmaceutical care provided for the patient. There is some doubt that issuing a prescription to continue medical treatment ordered by the doctor should strictly follow the original, i.e. doctor's, instructions or weigh them at will. The scope of the pharmaceutical care includes conducting pharmaceutical consultations/interviews, performing medication reviews together with assessment of the efficacy of pharmacotherapy prescribed for the patient, preparing an individual pharmaceutical care plan with regard to the patient's drug-related problems identified during drug reviews and consultations. Point 4 contains indications for conducting diagnostic tests by the pharmacist and they will be specified by the Minister of Health in the regulations issued on the basis of art. 4. Point 5 refers to the possibility of issuing prescriptions to maintain continuity of medical treatment (15). The cited definitions preceding the interpreted

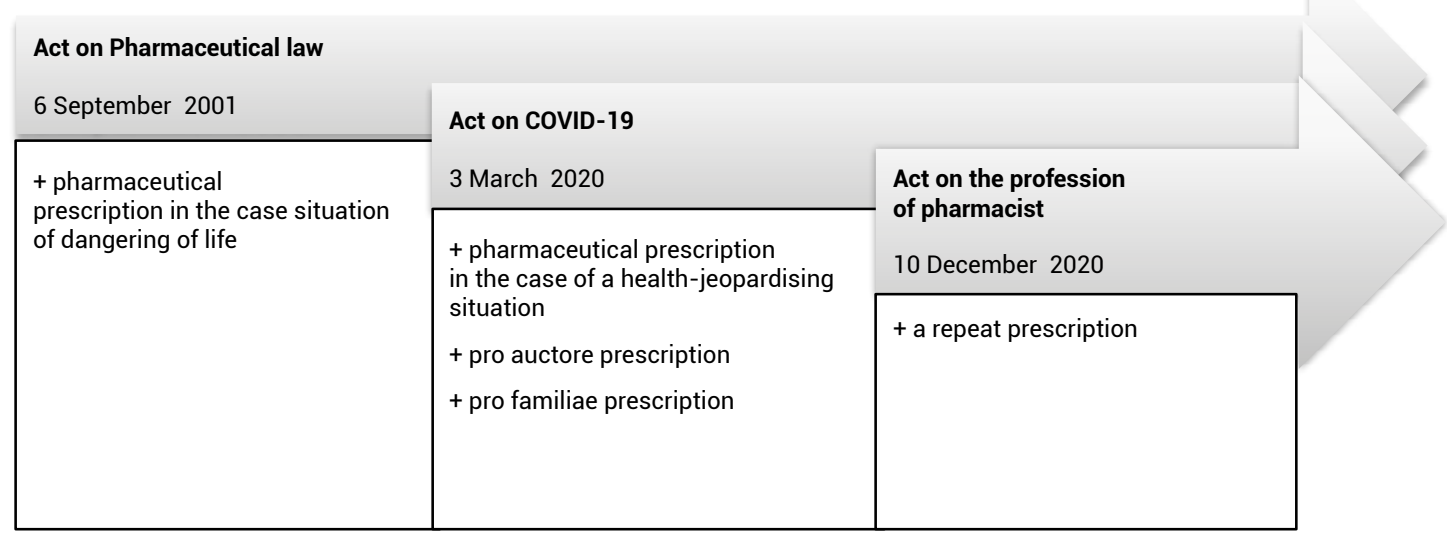

Figure 1. Extension of the pharmacist`s prescribing powers. Legal status 2020/2021. 
entry (point 5) reflect a wide range of pharmaceutical care provided for the patient. Even the possibility of performing diagnostic tests (or their ordering) as well as their interpretation is a great novelty in the scope of the pharmacist's occupational powers.

Yet, an essential question still awaits an answer, i.e. whether it is necessary to go through all the above-named points of the pharmaceutical care scope (fulfill them, possibly check or implement) in order to be able to issue a repeat prescription. By definition of pharmaceutical care, the first assumption can be readily made that there is real doctor-pharmacist cooperation during a patient's treatment. In this way, the pharmacist becomes familiar with the doctor's stratification of medical treatment. Then, it is much easier for the pharmacist to issue a repeat prescription as the next stage of treatment originally launched by the doctor or maintain its continuity. However, the remaining points are still left for interpretation. The legal entries may imply that a pharmacist's decision whether to issue a prescription to ensure continuity of treatment ordered by the doctor should follow performing diagnostic tests, e.g. taking blood pressure and other steps (e.g. diagnostics) within the scope of pharmaceutical care. Naturally, the doctor's consent should be obtained prior to such procedures.

The entries to the Act on the profession of pharmacist in chapter 7 introducing amendments in art. 83 point 9 specify the requirements that should be met to issue a repeat prescription. A prescription which is written for the purpose of continuity of the doctor's order is issued by the pharmacist as an electronic prescription on the basis of the originally issued prescription stored in the Medical Information System which contains information concerning the treatment and ensures continuity of the originally prescribed and clearly defined medicinal product, a food product for particular nutritional use or a medical product. Issuing a repeat prescription by the pharmacist requires access to the Electronic Platform for Collection, Analysis and Sharing of digital resources about Medical Events (P1 system). In the case when there is no access to the system, it is possible to issue a paper prescription. Its original form, however, as well as other data/information about the patient are stored in this system. In such circumstances, obtaining this information or even the doctor's data by the pharmacist becomes problematic and telephone consultation with the doctor to discuss the continuity of a patient's medical treatment may be difficult. It appears that a communication system is indispensable.

A repeat prescription may be written within a maximum of 12 months since the date of its original issue by the doctor. Thus, a patient on certain medication has quite a lot of time to seek continuity in a pharmacy if it is indicated. The amount of a medicinal product, food product for particular nutritional use, or a medical product must not exceed the amount necessary for a 360-day using period. Naturally, the amount is calculated on the basis of the dosage specified by the doctor. A repeat prescription may be issued for dispensing medication of the Rx category and the amount of a medicinal product on one prescription must not exceed the amount necessary for use in the period of time specified by the doctor. A repeat prescription contains information about the payment specified by the doctor unless the doctor decides to change the payment (15). The interpretation of this issue is quite extensive and not entirely transparent. It remains in agreement with the principle, yet, many possible situations, e.g. changes in the level of payment at a certain point in time, would only make this process more difficult. This entry is not an entirely commonplace and rational principle that has been substantively defined for patients; however, it is of great importance.

\section{CONCLUSION}

Authorizing pharmacists to issue new types of prescriptions and therefore become more involved in the course of therapy of a treated patient is a just decision. In addition, the COVID-19 pandemic forces pharmacists to reinvent their roles and intensifies the pharmaceutical practice, whereas great shortages of the health care workforce these days make this initiative rational and helpful. Regulations specify that pharmacists licensed to practice pharmacy may issue prescriptions for themselves and their family, they are also allowed to issue pharmaceutical prescriptions and repeat prescriptions to ensure continuity of medical treatment. However, one should make certain assumptions about this occupational power. This possibility ought not to be interpreted as taking over a doctor's professional duties, e.g. diagnosing a patient's condition. This occupational power is intended to streamline the procedure of supplying medication to those in need, which is clearly defined in the legislation under the term: pharmaceutical care (consisting of specified points). When issuing a repeat prescription, a pharmacist is at the same time responsible (under these circumstances together with the doctor) for the effects of his/ her actions. Therefore, while practicing prescribing, pharmacists should be aware of the current results and efficacy of undertaken treatment, the patient's current condition, and medications the patient is on. 
They should also be able to interpret test results and combine them with clinical knowledge. This procedure must be safe for the patient. Therefore, to ensure this, the pharmacist may also do the tests, analyze pharmacotherapy and consult the attending doctor to discuss further details, if necessary. The doctor may take this opportunity to confirm the number of repeat prescriptions (issued by the pharmacist) and types of medicines which may be prescribed in this way. Therefore, doctors who have much more opportunity to cooperate with pharmacists should also be familiar with these principles.

\section{CONFLICT OF INTEREST}

The authors declare no conflicts of interest.

\section{REFERENCES}

1. https://www.money.pl/gospodarka/farmaceutawystawi-pacjentowi-recepte-na-leki-refundowane6403902117099649a.html. (accessed 30.12.2020) (in Polish).

2. https://cowzdrowiu.pl/aktualnosci/post/przezpol-roku-wystawiono-275-mln-e-recept-dla25-mln-pacjentow. (accessed on 2.01.2021) (in Polish).

3. https://www.rynekaptek.pl/marketing-izarzadzanie/w-grudniu-2020-ubylo-27-aptekw-ciagu-calego-ubieglego-roku-prawie-400-aw-2-lata-ponad-1000,41545.html. (accessed on 5.01.2021) (in Polish).

4. https://www.gov.pl/web/zdrowie/radaministrow-przyjela-dokument-polityka-lekowapanstwa-20182022. (accessed on 5.01.2021) (in Polish).
5. Bond C., Matheson C., Williams S., Williams P., Donnan P.: Br. J. Gen. Pract. 50, 271 (2000).

6. Cooper R.J., Anderson C., Avery T., Bissell P., Guillaume L., et al.: Health Policy. 85, 277-292 (2008).

7. Emmerton L., Marriott J., Bessell T., Nissen L., Dean L.: J. Pharm. Pharm. Sci. 8, 217-25 (2005).

8. The act of 15 July 2011 on the professions of nurse and midwife. Dz.U. 2020 poz. 562 (uniform text) (in Polish).

9. Regulation of the Minister of Health of 23 December 2020 on prescriptions Dz.U. 2020 poz. 2424 (in Polish).

10. The Act of 12 May 2011 on the reimbursement of medicines, foodstuffs intended for particular nutritional and medical devices. Dz. U. 2020 poz. 357 as amended (uniform text) (in Polish).

11. The Act of April 15, 2011 on medical activity. Dz. U. 2020 poz. 295 (uniform text) (in Polish).

12. The Act of September 6, 2001, on Pharmaceutical Law. Dz.U. 2020 poz. 944 (uniform text) (in Polish).

13. Act of March 2, $2020 \mathrm{r}$. Of specific embodiments related to the prevention, preventing and combating COVID-19, and other infectious diseases caused by these emergencies. Dz.U. 2020 poz. 374. (in Polish).

14. Regulation of the Minister of Health of April 17, 2020 amending the regulation on prescriptions. Dz.U. 2020 poz. 690 (in Polish).

15. Act of 10 December 2020 on the profession of pharmacist. Dz.U. 2021, poz. 97 (in Polish).

16. The Act of 27 August 2004 on healthcare services financed from public funds. Dz.U. 2020 poz. 1398, as amended (in Polish). 